\title{
LA RELEVANCIA DEL LEVANTAMIENTO DE UNA BUENA DATA PARA LA INVESTIGACIÓN TURÍSTICA
}

\author{
José Pazos Miranda
}

\section{RESUMEN}

El presente artículo constituye un informe del levantamiento de data sobre la base de cuestionarios debidamente elaborados y aplicados a los diferentes establecimientos de servicios de hospedaje, agencias de viajes y restaurantes en la ciudad del Cusco, en el Valle Sagrado y en el distrito de Machu Picchu.

Palabras clave: restaurantes turísticos, industria hotelera, agencias de viajes, Cusco, Valle Sagrado, Machu Picchu.

\section{INTRODUCCIÓN}

El turismo es una de las actividades más importantes para la economía del país, gracias a su gran dinamismo y capacidad de desarrollo, lo que claramente se refleja en la Región Cusco.

En el presente período, el turismo ha surgido como una actividad económica de primer orden en todos los países del mundo. Todos reconocen su gran repercusión social, política y económica en el desarrollo de los pueblos.

Se incluye aquí un informe del levantamiento de data sobre la base de cuestionarios debidamente elaborados y aplicados a los diferentes establec- imientos de servicios: hospedajes, agencias de viajes y restaurantes, cada uno de ellos con sus categorizaciones y características propias, en la ciudad del Cusco, en el Valle Sagrado y en el distrito de Machu Picchu.

La información que se aporta es data sobre los servicios turísticos y está relacionada con la demanda y la capacidad instalada tanto en la industria hotelera como en restaurantes turísticos. Asimismo se ha desarrollado un instrumental para evaluar la calidad del destino Cusco y la industria conexa a la actividad turística, utilizándose los métodos Servqual (Service Quality) y Servperf (Service Performance).

Se ha podido observar que existen todavía diferentes establecimientos, tanto en el sector hotelero como en el de restaurantes y agencias de viajes, que aún no están empadronados en la base de datos de la Dirección Regional de Comercio Exterior y Turismo - Cusco (Dircetur).

A continuación mencionamos algunas estrategias empleadas para poder realizar las encuestas a los propietarios, ejecutivos, jefes de línea, personal operativo y turistas. En principio encontramos muchas dificultades y desafíos en la aplicación de los cuestionarios pertinentes al personal y a los turistas, a efectos de recoger la data requerida. En tal sentido desarrollamos mecanismos de empatía con las personas que nos iban a dar información, 
explicándoles que no representábamos a ningún organismo de control estatal y que la información que requeríamos era para la realización de estudios que finalmente iban a redundar en beneficio de sus representadas y de los usuarios de servicios. También tuvimos que coordinar sus tiempos libres y estudiar sus estados de ánimo.

Seguidamente detallamos algunos mecanismos en la obtención de la data correspondiente.

\section{RESTAURANTES TURÍSTICOS}

Primero se delimitó la ubicación de los restaurantes turísticos dentro del Centro Histórico del Cusco, haciéndose la distribución y organización correspondiente con el personal encargado de aplicar las encuestas, con el fin de evitar duplicidad en las entrevistas. Al comparar la base elaborada por nosotros con la brindada por Dircetur comprobamos que existen restaurantes turísticos que no figuran en los padrones de este organismo rector.

También nos enteramos, por información que nos proporcionaron algunos propietarios, que sus negocios se encontraban en proceso de calificación, otros no habían realizado ningún trámite por considerar que no les significaba mejoras económicas, y algunos estaban en proceso de cambiar de razón social.

\section{Comentarios}

- Existe un buen porcentaje de restaurantes turísticos categorizados y no categorizados en el Centro Histórico del Cusco que son gerenciados por personas que no son profesionales, aunque que sí tienen experiencia en estos negocios.

- Se evidencia una falta de conocimientos académicos en lo referente a gestión y organización: sistemas, marketing, costos y otras herramientas necesarias para el buen manejo de una empresa.

\section{INDUSTRIA HOTELERA DEL CUSCO, VALLE SAGRADO Y AGUAS CALIENTES}

Se comparó la base elaborada por nosotros con la información proporcionada por Dircetur referente al empadronamiento de hoteles, faltando actualizar lo concerniente a establecimientos en Cusco, Valle Sagrado y Aguas Calientes, unos en proceso de apertura y otros en trámite de empadronamiento y formalización. Algunos empresarios nos manifestaron que tenían la expectativa de que este trabajo sirviera para aportar a la mejora de sus establecimientos y optimizar el servicio a los turistas.

Otros ejecutivos, propietarios y personal operativo se negaron a brindar información por creer que podría ser entregada a la competencia; por lo tanto tuvimos que obtenerla utilizando otros mecanismos como, por ejemplo, entrevistas directas con los accionistas.

Hemos encontrado establecimientos que no abonan los puntos por productividad a sus trabajadores, quienes son contratados temporalmente, generando en ellos ansiedad y preocupación por la incertidumbre de la inestabilidad laboral.

Los cuestionarios a los usuarios de los establecimientos de hospedaje fueron aplicados en los terminales terrestres, aéreos y ferroviarios al momento de su embarque a otros destinos. Esta metodología fue utilizada con el fin de no perturbar u ocasionar conflictos innecesarios.

Observamos que algunos propietarios de centros de hospedaje de Aguas Calientes realizan el monitoreo de los servicios que prestan desde el Cusco y esporádicamente se constituyen en el lugar, delegando la responsabilidad a sus trabajadores multifuncionales (por las diferentes actividades que prestan en estos centros de hospedaje), dejando mucho que desear en lo referente a la calidad de los servicios que brindan a los turistas.

\section{AGENCIAS DE VIAJES}

Realizamos el monitoreo correspondiente para obtener información sobre el antes y el después de los servicios de las agencias de viaje; primero, en referencia a las expectativas y percepciones de los turistas antes de recibir dichos servicios y, luego, organizándonos y esperándolos con la mayor paciencia para abordarlos e interrogarlos sobre la atención recibida. 
Un buen porcentaje de los directivos de agencias, al igual que su personal ejecutivo, nos facilitaron la tarea porque les explicamos que se trataba de un trabajo que buscaba la mejora de sus servicios y que pudieran satisfacer las exigencias de los turistas.

\section{COMENTARIOS Y ALGUNAS APRECIACIONES}

- Las buenas relaciones con algunos propietarios, ejecutivos, personal de línea y operativo nos permitieron tener acceso a la data requerida.

- Logramos en gran medida hacer comprender a propietarios y ejecutivos que los cuestionarios eran para el levantamiento de la data y para realizar estudios conducentes a mejorar los servicios que prestan sus establecimientos y no para ofrecer información a la competencia, como ellos creían.

- Realizamos visitas periódicas de consumo para observar la rotación de mesas en los restaurantes en diferentes horarios, así como la afluencia de público.
- Observamos que muchos establecimientos de hospedaje son gerenciados empíricamente.

- Inferimos que el desempeño de los trabajadores con contratos parciales refleja e incide mucho en el servicio que prestan, no siendo el mejor mecanismo para su crecimiento profesional.

- Comprobamos que en algunos servicios de hospedaje los trabajadores no están debidamente identificados con sus fotochecks, uniformes $\mathrm{u}$ otros elementos de reconocimiento, lo que conlleva la desconfianza de los turistas.

- Confirmamos el desconocimiento de los agentes de viajes sobre alternativas de turismo como el vivencial, el de aventura, el educativo, entre otros.

- La Dircetur debería contar con la data real y actualizada de estos establecimientos.

\section{Bibliografía}

Galindo Cáceres, Jesús (coordinador)

1998 Técnicas de investigación en sociedad, cultura y comunicación. México: Prentice Hall-Pearson Education-Addison Wesley. 